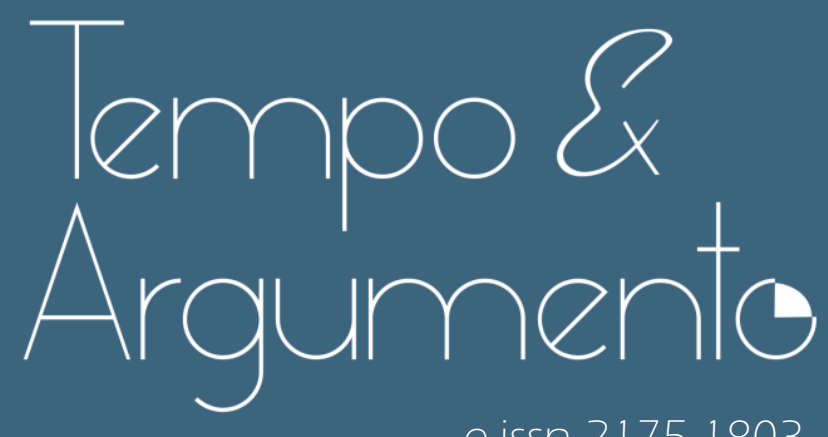

e-issn 2175-1803

\title{
Cultura é Comum
}

Tradução do artigo "Culture Is Ordinary".

Publicado no Key Words: A Journal of Cultural Materialism, n. 6, p. 8 - 15, 2008.

Autor:

粎 Terry Eagleton

Professor da Universidade de Lancaster.

Lancaster - REINO UNIDO

t.eagleton@lancaster.ac.uk

Tradutor:

- André Alves Pereira

Mestre em História pela Universidade Federal de Santa Catarina.

Florianópolis, SC - BRASIL

alvespereira.andre@gmail.com 
Foi Raymond Williams, como se sabe, quem inventou o termo "materialismo cultural", uma expressão que tomo como sinal, entre outras coisas, de que ele era e não era marxista. Por um lado, como os marxistas, ele era filosoficamente um materialista, uma afirmação que não deveria ser entendida como significando que ele gostava de possuir bens materiais. Pelo contrário, ele vivia um tipo de existência bastante austera e, às vezes, parecia estranhamente relutante em acender a luz na sala de estar de sua cabana, de modo que se acabava falando com ele na penumbra como se estivesse participando de uma sessão espírita. Nunca o vi beber mais do que meio litro de bitter de cada vez, e ele ficou um pouco alarmado quando os outros ao seu redor o fizeram (muitas vezes dei motivos para alarmá-lo a esse respeito). Talvez houvesse alguma memória das origens na cultura de capela galesa em ação aqui. O "materialismo" também não deve significar que ele não acreditava nos assim chamados valores espirituais - o trabalho de toda a sua vida foi sobre eles -, apenas que ele via esses valores trabalhando em contextos sociais e históricos. A discussão é sobre o que entendemos por valores espirituais, não se eles existem. Nesse sentido, assemelha-se à discussão sobre literatura, não à discussão sobre OVNIs.

Sob outra perspectiva, Raymond sempre foi bastante cético em relação às noções marxistas convencionais de cultura, suspeitando, como ele pensava, que relegar a cultura à chamada superestrutura significava desmaterializá-la e diminuir seu valor. Considero que ele estava errado sobre isso, mas foi o que se poderia chamar de erro produtivo, pois resultou nesse projeto fértil conhecido como materialismo cultural, cujo objetivo era investigar não artefatos isolados, mas os processos materiais, relações e instituições da própria cultura. Uma questão a se levantar é como esse projeto difere da sociologia convencional da cultura. Suspeito que a resposta é que a sociologia tradicional da cultura olha para o que se poderia chamar de produto externo do artefato cultural, seu ambiente social, enquanto Raymond estava interessado em ver como esse contexto, por assim dizer, entrou no próprio artefato, se infiltrou em seu produto,

\footnotetext{
1 Texto da palestra de abertura que abriu o 20 fim de semana anual Raymond Williams no Wedgwood Memorial College, de 2 a 4 de maio de 2008. Esses cursos são realizados em associação com a WEA (Workers Educacional Association) e a RWMF (Raymond Williams Memorial Fund).
} 
nas suas formas e conteúdos, de maneira a superar essa divisão entre interno/externo bastante simplória. Como você pode rastrear as condições sociais de uma obra de arte dentro da própria obra em sua forma e estrutura, sintaxe e textura? Esse é um procedimento difícil de operar, embora o trabalho de Raymond sobre o drama possa nos fornecer alguns exemplos. Ele poderia traçar uma mudança na perspectiva ideológica ou nas relações sociais em uma mudança de técnica de palco - do, digamos, naturalismo para expressionismo.

Ou pense na maneira como toda obra literária codifica algum sentido implícito de seu público potencial e de suas relações com eles - se esse público é coletivo (como na epopeia) ou individual (como na lírica), se deve ser instruído ou persuadido, se a obra deve ser entendida como igual, inferior ou superior ao público, se ela chama à ação ou ao quietismo, e assim por diante. Como, por exemplo, as obras literárias mudam quando se percebe que suas relações sociais foram alteradas, e que, diferentemente do que chamamos de obras de arte clássicas, elas não têm público estabelecido ou reconhecível - que seus leitores são anônimos, e que o escritor, como Shelley observa, é um rouxinol cantando no escuro, ou que o narrador está literalmente falando no escuro, como no início do superestimado Coração das Trevas, de Conrad? Qual a diferença entre obras que podem tomar certo público identificável como um dado e aquelas que devem, por assim dizer, produzir seus próprios leitores, moldar suas próprias condições de recepção? Como tudo isso pode ser detectado na própria obra de arte? E como tudo isso se relaciona com as condições de mercado, as condições de produção? Devo acrescentar que o conceito de materialismo cultural, é claro, também possui suas próprias condições materiais ou históricas - quero dizer, é difícil não ver a cultura como, em certo sentido, material quando se tem a ascensão da chamada indústria cultural - quando a cultura é, obviamente, uma questão de capital, tecnologia, mercados e a produção básica de mercadorias.

Nesse sentido, talvez, Graham Norton² seja um materialista cultural cardcarrying. O ponto, no entanto, é que, embora os críticos convencionais estejam

\footnotetext{
2 Graham Norton é um apresentador de um conhecido programa humorístico do canal BBC, no formato tradicional de entrevistas individual com auditório. 'Card-carrying' foi um termo popularizado em inglês durante a perseguição macarthista logo após a segunda guerra mundial para se referir a pessoas que supostamente disseminavam mensagens comunistas pela sociedade.
} 
perfeitamente prontos para reconhecer isso no caso do Britain's Got Talent ou no caso da Madonna, eles são notavelmente mais relutantes em admitir o argumento quando se trata de Dante ou Shostakovich. O materialismo cultural é muito bom para as massas, mas o idealismo cultural é a província da elite.

Penso que o termo "materialismo cultural", no entanto, pode ser usado em outro sentido. Você pode ser um materialista sobre cultura; mas você também pode abordar a cultura como um materialista, e acho que a expressão pode significar as duas coisas. (Ou pelo menos vou fazer com que signifique as duas coisas.) Isso faz uma diferença importante na forma como você avalia a cultura nos assuntos humanos em geral. O materialismo cultural, no sentido que acabei de descrever, classifica-o com muita seriedade: a cultura não é apenas um conjunto de obras de arte solitárias, é todo um setor de produção social, tão real e sólido e material quanto a criação de porcos e talvez até algum sentido mais importante. Por outro lado, o materialismo cultural, avaliado por um materialista, está menos convencido da centralidade da cultura. Devo dizer aqui que a cultura é realmente uma daquelas ideias que é quase impossível não superestimar ou subestimar. Nesse sentido, sua equivalência mais próxima é o sexo. Homens e mulheres não vivem só de cultura. No sentido estreito, artístico e intelectual da palavra, a maioria deles não vive de maneira alguma; e mesmo no sentido mais amplo e generoso da palavra, que significa todo um modo de vida, que Williams fez tanto para promover, você pode afirmar que a cultura não é fundamental.

O que quero dizer com isso? Bem, eu acho muito significativo que nenhum dos problemas mais intratáveis que a humanidade enfrenta à beira do novo milênio é realmente, em um sentido muito específico, um problema cultural. Guerra, fome, drogas, doenças, crime, migração em massa, a chamada guerra ao terror, a devastação do planeta: é certo que todas essas questões são culturais no sentido de que em todas as questões que chamamos de humanas estão envolvidas em questões de significado, linguagem, valor e afins. Mas essa é uma definição tão ampla de cultura que é essencialmente inutilizável. Ela acaba não capturando nada. Termos que tentam cobrir tudo acabam sem significado. (Pense na pura inutilidade de dizer 'tudo é político', exceto para alguém que imaginava que a política estava confinada à Câmara dos Lordes.) Essas questões 
são em geral materiais e não culturais, mesmo que essa seja uma distinção difícil de fazer enquanto estão sendo vividas. Acho que o próprio Williams muitas vezes não estava suficientemente alerta para essa distinção, em parte por causa de sua ênfase (profundamente valiosa na maior parte) na experiência. É bastante seguro que não experimentamos o material e o cultural existentes como categorias separadas. Morrer de fome, por exemplo, é quase sempre uma questão cultural - de um lado, porque a fome quase nunca é causada por escassez de alimentos, mas pela incapacidade das pessoas de comprar comida, o que é claramente cultural, em sentido amplo; de outro, porque a fome raramente ocorre nas democracias, uma vez que os governos eleitos democraticamente não podem sumir com os famintos. Mas morrer de fome não é cultural, no sentido de que promover a língua galesa ou obstruir uma dança ou tatuar uma suástica no pescoço ou rezar na direção de Meca é cultural. Colocar comida em seu corpo é uma necessidade biológica; se é pão ou chapati, é um assunto cultural.

É isso que tende a ser negado pela corrente de pensamento pós-moderno conhecida como culturalismo. Para o culturalismo, a cultura vai até o fim. A coisa vai de uma ponta a outra. Essa é uma forma de reducionismo, uma estratégia conceitual que os pós-modernistas devem não aprovar; e é uma estratégia que corre o risco de esvaziar o termo "cultura" de todo significado tangível, para não falar do fato de que não é verdadeira. Não é verdade, porque, quaisquer que sejam os seres humanos, eles são, em primeiro lugar, objetos materiais naturais; e qualquer coisa mais interessante que possamos abordar - chame de história - precisa reconhecer sua dependência dessa base material, de nossa condição efêmera, vulnerável, frágil e viva, para que não se mostre exagerada e, em última análise, autodestrutiva.

Há pessoas que sempre tiveram problemas para aceitar esse fato e muitas delas são conhecidas como americanas. A ideologia americana é virulentamente hostil à ideia de limite material: "você vai conseguir se tentar", "o céu é o limite" e coisas assim são absurdos ideológicos. Há muito voluntarismo puritano - o culto à vontade rígida, solitária e neuroticamente ativa - à espreita por trás disso. Os Estados Unidos estão apaixonados por uma infinidade de desejos faustianos, 
que considera a materialidade mais um obstáculo do que um conjunto de restrições criativas. A aventura criminosa no Iraque tem muito a ver com esse culto idealista enlouquecido do "eu-posso-eu-consigo". A sociedade mais vorazmente materialista do planeta é idealista em sua essência, e as duas coisas não estão de modo algum desconectadas. Aliás, o chamado radicalismo islâmico é uma forma de culturalismo, porque vê valores e crenças espirituais como a dinâmica da história. Osama Bin Laden não é exatamente um materialista. Mas a chamada guerra contra o terror não é, em primeiro lugar, uma questão cultural, assim como a guerra na Irlanda do Norte não era sobre infalibilidade papal.

Creio que Raymond Williams sempre entendeu isso, apesar de seu imenso investimento na noção de cultura, porque ele era o que você poderia chamar de materialista filosófico nato. Como homem, ele tinha um extraordinário senso do processo material, vivo, delicado, perceptivo, quando se tratava de cavar e fazer cercas nas Montanhas Negras ou observar o curso complexo de um rio ou apreender os meandros do trabalho manual de outra pessoa. Mas isso também era uma questão de conviç̧ão. Em grande parte, devido a sua origem rural, ele tinha um grande interesse pela natureza, ecologia e meio ambiente muito antes de esses termos estarem na moda. De fato, foi na casa dele que ouvi pela primeira vez a palavra 'ecologia'. Ele estava mergulhando no livro escolar de biologia do seu filho e me perguntou se eu sabia o que a palavra significava. Acho que respondi que era o estudo dos insetos. Carinhosamente ignorando esse absurdo, ele observou que era o estudo da interrelação de elementos em um sistema vivo - e se podia ver como essa investigação logo capturou sua imaginação.

Penso que Raymond teria concordado com a proposição de que a cultura não é a nossa natureza, como sustentam os culturalistas pós-modernos, mas (uma importante nuance de diferença aqui) a cultura é da nossa natureza. Todos os animais humanos nascem, por assim dizer, prematuramente, incapazes de cuidar de si mesmos; e se a cultura, no sentido de cuidar, amamentar e nutrir, não os afeta imediatamente, eles certamente vão morrer. Nascemos com um buraco ou uma lacuna em nossa natureza biológica, em que a cultura deve estar, 
como uma espécie de excedente ou suplemento que, como o suplemento derridiano, é ao mesmo tempo necessário.

Essa cultura, no amplo sentido do termo, nos permite ir muito além dos limites de nossos corpos materiais. Seguramente, a cultura é a maneira como estendemos esses corpos para um contexto global. Bancos, tratados diplomáticos e trocas telefônicas são realmente extensões de nossos corpos. Como temos a linguagem, ou seja, todos os tipos de conceitos complexos à nossa disposição, podemos nos tornar seres verdadeiramente universais, realizando todo tipo de coisas surpreendentes que não são possíveis para toupeiras ou texugos. Toupeiras e texugos não conseguem sair de seus próprios corpos como animais linguísticos; o que eles fazem é praticamente restrito por seus ciclos biológicos. Não quero ser odiosamente paternalista aqui - quero dizer, tenho certeza de que texugos e peixinhos dourados são perfeitamente decentes à sua maneira -, mas vamos encarar o fato: são extremamente limitados por não possuírem cultura. Quero dizer, eles sequer conseguem construir uma arma nuclear. Quão incivilizado isso pode ser? A menos que eles estejam sendo muito discretos sobre o assunto.

E esse com certeza é o ponto. Os próprios poderes que nos permitem criar também nos permitem destruir. No que diz respeito ao animal linguístico, é difícil ter Tennyson sem Trident. Nossa linguagem nos permite um acesso muito mais próximo às coisas e a uns aos outros do que o mero contato físico; os relacionamentos sexuais, por exemplo, são principalmente sobre conversar. (Ou estou perdendo alguma coisa?) Mas a linguagem ou o pensamento conceitual também nos separa e corre o risco de nos afastar do mundo. Como a linguagem ou a cultura nos desloca das restrições sensuais do nosso corpo, sempre corremos o risco de nos desenvolver rápido demais, nos autoenganando e nos conduzindo a nada. Os gregos antigos entendiam isso muito bem. É difícil matar alguém com as próprias mãos, já que isso provavelmente apenas te deixaria doente. Inibições sensoriais entrariam em ação. Mas já é um tanto mais fácil queimar crianças árabes até a morte de um ponto distante.

A propósito, é sobre isso que trata a doutrina teológica da queda. Atingimos poderes criativos ou formas de conhecimento que também ameaçam nos 
destruir. Assim como todas as melhores quedas, a Queda do Éden foi para cima e não para baixo - uma Queda na história, língua, cultura e consciência. O que, obviamente, é muitíssimo precioso para nós, além de potencialmente letal. É por isso que a Queda da graça é tradicionalmente conhecida como Feliz Queda, ou felix culpa. Mas é uma queda ainda assim.

O próprio Raymond não se interessou por grandes generalidades como essa à qual acabei de ceder. Na verdade, ele era notavelmente cismado com elas. Mesmo quando falava abstratamente, ele tinha uma maneira estranhamente atraente de imbuir essas abstrações com certa força e concreção. Seu estilo literário faz isso o tempo todo. Mas acho que ele teria sido avesso ao culturalismo, como teria reconhecido se tivesse vivido em nosso tempo, no qual, em certo sentido, a cultura se tornou mais comum do que nunca. Não necessariamente no sentido pós-moderno, embora a cultura pós-moderna seja certamente em geral mais popular e vernacular do que Stendhal ou Strindberg. Mas esse populismo cultural às vezes revela a qualidade niveladora e indiscriminada da mercadoria, que não é o tipo de cultura popular que Raymond tinha em mente. Se é inclusiva, anti-hierárquica, despretensiosa, amiga do consumidor, anti-elitista, aberta a todos os interessados, isso acontece em grande parte porque o mercado também o é.

Quero dizer que a cultura se tornou ainda mais comum em um sentido político. O que é surpreendente, se vocês observarem os três movimentos políticos que dominam a agenda global desde o final do século 20 - o nacionalismo revolucionário (de longe a corrente revolucionária de maior sucesso da modernidade), o movimento de mulheres e os vários conflitos étnicos - a cultura, no sentido amplo de linguagem, signo, valor, identidade, pertencimento, tradição, modo de vida e assim por diante, é absolutamente central. A cultura se torna o idioma em que as demandas políticas são enquadradas - o que não é de forma alguma verdade para as lutas industriais ou de classe. Não é tanto a cultura ou identidade das pessoas (uma questão cultural) que está em jogo nessas lutas de classe e muito mais sua sobrevivência e bem-estar muito materiais. É por isso que é ainda mais admirável que os trabalhadores tenham se engajado tão intensamente ao longo dos séculos em formas de cultura literária e artística, pois 
eles realmente não têm o mesmo papel central a desempenhar em suas lutas tal como a fala de uma língua nacional, uma forma religiosa de vida ou a literatura indígena têm para o movimento de libertação nacional do terceiro mundo. Alguém certa vez descreveu o nacionalismo revolucionário como uma invenção de tipos literários. É um modo muito poético de política. Vocês não colocariam Padraic Pearse ${ }^{3}$ no comitê de saneamento.

Em outras palavras: no século XX, a cultura passou de parte da solução para parte do problema. No século XIX, a cultura, significando os valores que compartilhamos mais profundamente, poderia ser invocada como uma base de unidade sobre a qual todos poderíamos nos reunir, independentemente de nossas divisões materiais, sociais e políticas. Sob essas divisões, havia uma essência humana compartilhada, e sua expressão era conhecida como cultura. Se essa era uma estratégia flagrantemente ideológica, projetada para mascarar conflitos reais em nome da harmonia cultural, também era, a seu modo, uma concepção nobre e generosa. (Não devemos esquecer que Karl Marx tinha a mais profunda admiração pela mais revolucionária de todas as classes sociais, a classe média liberal, que é a classe que produziu essa ideia.) A cultura aqui era uma espécie de solução espiritual para os males sociais. No século XX, no entanto, a própria cultura se torna um terreno de contenção política. De fato, você pode definir cultura nesse sentido como aquilo pelo que as pessoas estão preparadas para matar. Ou morrer, se você preferir. Ninguém que eu saiba está preparado para morrer por Dickens ou Dostoiévski, exceto talvez algumas pessoas seriamente estranhas se escondendo em cavernas com vergonha de aparecer e mostrar seus rostos; mas muitas pessoas estão preparadas para morrer por sua identidade religiosa ou nacional, ou para matar por ela. A cultura é tão crucial quanto isso. E, no entanto, ao mesmo tempo, não é tão fundamental assim. Você não pode promover um idioma, dançar sapateado, escrever romances ou queimar pessoas em piras fúnebres se estiver morrendo de fome. A cultura, nesse sentido, é uma espécie de excedente. Pressupõe o trabalho humano, o que

\footnotetext{
Padraic Pearse foi um importante poeta, escritor, professor e revolucionário irlandês, considerado um símbolo nacional nas irlandas. Envolveu-se na luta pela independência irlandesa na chamada Revolta de Páscoa, foi conduzido à presidência do governo provisório revolucionário e acabou executado pelo governo britânico no mesmo ano, em 1916.
} 
por sua vez pressupõe muito mais. E esse, certamente, é um significado do materialismo cultural.

Agora sabemos que esse trabalho sempre envolveu exploração e infelicidade. Para cada catedral, uma fenda de ossos. Para cada sinfonia esplêndida, muito trabalho ingrato e árduo. Cultura e barbárie são, nesse sentido, lados da mesma moeda - em oposição à visão convencional de que são sequenciais e não sincrônicas, isto é, que a cultura ou a civilização acompanha a barbárie, está permeada de barbárie. Isso é verdade até o momento - mas a verdade é que a violência necessária pela qual a humanidade salva a civilização do caos não é um assunto resolvido de uma vez por todas. Pelo contrário, essa precária vantagem sobre a Natureza, conhecida como civilização, deve ser constantemente sustentada - o que significa que o ato primordial de violência está em andamento. Como Freud argumenta, civilização ou cultura necessariamente exige muita repressão. E o que reprime mais notavelmente é a violência e a agressão que a produziu. O mesmo para Freud é verdadeiro para os indivíduos: o que é realmente escandaloso em seu trabalho não é a ideia de sexualidade infantil, que muitas pessoas já conheciam há muito tempo, sobretudo a dos bebês, mas o fato de que, para pensar, agir e falar como os indivíduos que somos, uma quantidade enorme do que entrou em nossa formação como sujeitos humanos deve necessariamente ser reprimida. A repressão é, portanto, boa para nós, embora em excesso nos deixe doentes (neurose). A psique individual nunca deixará de carregar as cicatrizes lívidas dessa repressão original, assim como a civilização "sublima" essa violência original no Estado, expulsando-a para se defender.

Uma crítica adequadamente materialista, portanto, seria uma que, por assim dizer, radiografasse as obras da civilização, a fim de revelar os traços ocultos da barbárie pela qual se formaram. O que não é de modo algum negar que essas são realmente obras da civilização, que a civilização é indescritivelmente preciosa, que não é apenas uma "máscara" para a violência e outras fantasias infantis ultra-esquerdistas. E acredito que isso faz parte do que Raymond tentou fazer. Há, no entanto, outra história para contar sobre cultura, que não é tão proeminente em seu trabalho. Quando, no período da modernidade 
inicial, as obras de arte deixavam de ter a função sobretudo pública que tiveram, podiam sempre recorrer a um caso engenhoso para justificar essa embaraçosa falta de função pública. Os artistas poderiam dizer: bem, a arte não parece ter um papel importante em todo o lugar, como teve quando o bardo cantou sobre as vitórias militares da tribo, ou quando o tribunal encomendou uma máscara, ou quando seu patrão aristocrático pagou você para desenhá-lo posando com muitas vacas ao fundo para mostrar o quão extravagantemente rico ele era.

Mas, continua o argumento, esse é o ponto. O ponto da arte é sua gloriosa inutilidade. É a única coisa que resta em uma sociedade dominada pela utilidade, valor de troca e razão instrumental, que não possuem nenhum sentido. Isso ocorre porque seu objetivo reside nela mesma, sua verdade é ela própria. A arte é esse tipo peculiar de coisa que carrega seus fins, princípios, razões, origens e fundações inteiramente em si mesma. Não vê necessidade de justificar sua existência perante um tribunal sombrio da História, Utilidade, Produção, BemEstar Público, Melhoria Moral e todas essas outras versões tediosas do superego social. Seu propósito reside simplesmente em seu próprio prazer sensual e espiritual, enquanto continua se conjurando de suas próprias profundezas insondáveis apenas pelo prazer de fazê-lo. Como tal, junta-se a uma classe de objetos extremamente raros que existem igualmente apenas para seu próprio deleite, que são radicalmente autotélicos e que incluem Deus, o mal e os seres humanos. Seres humanos, pelo menos, como poderiam ser sob condições políticas modificadas, quando não mais fossem instrumentos, mas fins em si mesmos.

Numa espantosa ironia, então, a arte se torna uma imagem da vida boa precisamente por não ter nenhum objetivo. Prefigura uma situação na qual seríamos libertados da maldição do trabalho (a única razão para se tornar socialista, é claro, é que você se opõe a ter que trabalhar) e, em vez disso, como Oscar Wilde poderia ter dito, ficaria o dia inteiro vestindo roupas largas e vermelhas e seria sua própria sociedade comunista. A arte é totalmente inútil, e nós também. Pelo menos deveríamos ser. A arte é um sinal de que a necessidade de brincar, excesso, excedente, extravagância, o estritamente desnecessário, o que ultrapassa o limite, estão realmente embutidos em nossa natureza. Nossa 
natureza é tal que gera cultura. (A análise mais sutil de tudo isso é conhecida como Rei Lear.)

Raymond não explorou particularmente essa dimensão utópica da cultura. Talvez fosse a cultura da capela em ação novamente. Independente do que tenha sido, ele certamente não era um Oscar Wilde, com quem compartilhava apenas a capacidade celta da eloquência. Mas seu trabalho fez algo de extrema importância. Ele reuniu dois sentidos da palavra "cultura", mostrando que a cultura no sentido da vida artística e intelectual de uma sociedade manifestava certas qualidades da vida, qualidades de ser, qualidades de relacionamento e criatividade, que precisavam ser generalizadas para a vida social como um todo, e a articulação ou ponte entre essas duas ideias de cultura, a maneira como a primeira seria transformada na segunda, seria a política. Atualmente, há departamentos de Estudos Culturais que parecem pensar que o estudo da cultura no sentido de formas de vida acabou com a cultura no sentido de exploração disciplinada da arte; e há departamentos acadêmicos mais tradicionais que acreditam que o oposto deveria ser o caso. Fazia parte da profunda generosidade de espírito de Raymond ter reconhecido há muito tempo que falso dilema era esse.

Universidade do Estado de Santa Catarina - UDESC

Programa de Pós-Graduação em História - PPGH Revista Tempo e Argumento Volume 12 - Número 31 - Ano 2020 tempoeargumento@gmail.com 